\title{
Role of habitat definition on Aichi Target 11: Examples from New Caledonian coral reefs
}

\author{
Gairin Emma ${ }^{1,2}$, Andrefouet Serge 1, *
}

\author{
1 Institut de Recherche pour le Développement, UMR 9220 ENTROPIE (Institut de Recherche Pour le \\ Développement, Université de la Réunion, Centre National de la Recherche Scientifique), New \\ Caledonia \\ ${ }^{2}$ School of GeoSciences, The Grant Institute, University of Edinburgh, James Hutton Road, King's \\ Buildings, Edinburgh, EH9 3FE, UK
}

* Corresponding author : Serge Andrefouet, email address : serge.andrefouet@ird.fr

\begin{abstract}
:
The Aichi 2020 Biodiversity Targets are the backbone of many conservation projects. As the 2020 deadline is approaching, countries assess their progress. Target 11 (ABT11) calls for the protection of at least $10 \%$ of coastal and marine areas, while encouraging to focus on areas with particularly important habitats, notably for coral reefs. This target indirectly poses the question of the definition of habitats and their level of representation in Marine Protected Areas (MPAs). We hypothesized that success or failure in achieving the targets could depend on how habitats are defined and considered. To address this issue, the current level of protection with respect to ABT11 is quantified for a hierarchical inventory of coral reef habitats in New Caledonia, a country with complex governance and diverse coral reefs. At the country scale, ABT11 is met with respect to broadly-defined coral reefs due to the presence of large MPAs. However, reserves are too spatially limited to comply with ABT11 at the provincial scale. The results appear dependent upon the hierarchical level of precision used to define habitats. While reefs as a whole meet Target 11, specific habitats, defined at a more detailed description levels, have varying levels of protection; and some do not meet ABT11. The results highlight that assessments of the achievement of the 11th Aichi target strongly depend upon spatial scales and habitat classification, at least for coral reefs. The findings suggest that Aichi compliance assessments worldwide need to take into account variability and biases linked to habitat description.
\end{abstract}

Keywords : Convention on biological diversity, Millennium coral reef mapping, Geomorphology, Habitat, Conservation 


\section{Introduction}

In 2004, the Conference of the Parties of the Convention on Biological Diversity (CBD) put a strong emphasis on the role of marine and coastal protected areas (hereafter MPAs) for effective biodiversity conservation, and committed its members to create MPAs preserving $10 \%$ or more of each ecological region of the world by 2010 (UNEP/CBD/COP/DEC/VII/5). This ambitious objective was reiterated in 2010, where the CBD Parties endorsed, in Nagoya - the capital of the Aichi prefecture, in Japan -, the Strategic Plan for Biodiversity 2011-2020. This plan comprises of 20 Aichi Biodiversity Targets, which are organized under five strategic goals, so that "[by] 2050, biodiversity is valued, conserved, restored and wisely used, maintaining ecosystem services, sustaining a healthy planet and delivering benefits essential for all people" (UNEP/CBD/COP/10/27/Annex). As part of strategic goal C, the Aichi Biodiversity Target 11 (hereafter ABT11) states that, "by 2020, at least 17 per cent of terrestrial and inland water, and 10 per cent of coastal and marine areas, especially areas of particular importance for biodiversity and ecosystem services, are conserved through effectively and equitably managed, ecologically representative and well-connected systems of protected areas and other effective area-based conservation measures, and integrated into the wider landscapes and seascapes" (UNEP/CBD/COP/10/27/Annex).

The Aichi targets have been strong drivers of international and national conservation agendas over the past decade, and have led to a widespread mobilization of scientists. Work has notably focused on discussing the targets' value and feasibility [1-3], debating the effectiveness of the conservation programs that stem from the targets (e.g., the giant MPAs [4-5]), and investigating the interactions of the targets with other initiatives (e.g. with the United Nations Sustainable Development Goals [6]). In practice, the Aichi targets have guided marine conservation planners with representation targets. The goal of ecological representation is to have a representative sample of the full variety of biodiversity within a 
network of protected areas [7]. This is justified since biodiversity cannot be safeguarded if the protected areas do not represent well the range of conditions, species, and processes occurring on the conservation area. Following the representation criteria (and others, such as replication, connectivity, etc.), conservation objectives within MPA networks often include a certain percentage of the different habitats occurring in a given area (e.g., [8]).

The short text formally defining the ABT11 was open to interpretation in terms of the entities that needed protection, since, for instance for the marine realm, 'coastal and marine areas' or 'seascapes' could be perceived in various ways (see different 'seascape' definition in [9]). Several authors quickly suggested clarifications of the Aichi targets texts. For instance, Woodley et al. [10] recommended and confirmed the need to target the representation of ecoregions, sensu Spalding et al. (2007) [11]. The CBD itself also edited several documents in subsequent years to clarify the targets and provide guidelines to reach them. For instance, in the series of leaflets named 'Quick guide to the Aichi Biodiversity Targets' (available for Target 11 at https://www.cbd.int/doc/strategic-plan/targets/T11-quick-guide-en.pdf, [12]) the initial text 'include areas of particular importance for biodiversity and ecosystem services' was developed as 'such as areas high in species richness or threatened species, threatened biomes and habitats, areas with particularly important habitats (key biodiversity areas, high conservation value areas, important plant areas, sensitive marine areas etc.) and areas which are important for the continued provision of ecosystem services'. Furthermore, there are explicit references to coral reefs, seagrass, or mangroves, which are ecosystems or broad habitats implicitly nested within an ecoregion, and possibly along with other types of ecosystems. CBD stated that 'particular emphasis is needed to protect critical ecosystems such as tropical coral reefs, sea-grass beds, deep water cold coral reefs, seamounts, tropical forests, peat lands, freshwater ecosystems and coastal wetlands'. 
These clarifications and guidelines by CBD imply that finer granularity in ecoregion description, with habitat-level information, is useful and even needed. For tropical countries where coastal systems are vastly dominated by coral reefs, mangroves, or seagrass beds, the question of representation can be translated into a question of adequate representation of these habitats. For instance, New Caledonia, which is completely surrounded by a vast lagoon and coral reef systems, is evaluating, as part of a France-wide assessment, its compliance to Aichi targets specifically for its lagoon and coral reefs.

As the Aichi 2020 deadline is rapidly approaching, the number of studies aiming to quantify the level of achievement of conservation programs for both marine and terrestrial biomes increases. Governments aim to provide their achieved scores, which is the percentage of the representation of the entities of interests (biomes, ecoregion, ecosystems or habitats) within an MPA network. For instance, the Agence Française pour la Biodiversité (French Biodiversity Agency) has recently issued a first report on the ABT11 achievements for the coral reefs of the French overseas territories [13]. This French national marine assessment was conducted independently for each French overseas collectivities, a strategy which is justified since each coral reef region is characterized by its own biodiversity, as reviewed for instance for New Caledonia in the Western Pacific, Iles Eparses (or Scattered Islands) in the Western Indian Ocean and French Polynesia in the Central Pacific by [14-16] respectively.

With the increase in the number of case studies at various scales [17-19], new metrics are being proposed [20], and issues about the assessment methods are emerging [21-23]). Among the numerous biases that arise when evaluating progress towards the ABT11, we believe that a fundamental one can be related to habitat definition and classification, especially for the tropical countries that are characterized by extensive coral reef and lagoon areas. While the CBD texts explicitly mention coral reefs, mangroves, and seagrass beds, they do not provide clear definitions of these entities. This issue is not trivial, especially for coral reefs. There are 
multiple ways of describing and classifying coral reefs and their habitats [24]. The definition of a coral reef is a 6-page long section of the Encyclopedia of Modern Coral Reefs and can depend on geology, geomorphology, sedimentological, physical and ecological attributes taken together or separately [25]. Varied research and management interests in different geographical areas often lead to contrasted views when defining coral reefs and their spatial limits. An example is provided by Goldberg [26], who revisited the definition of atolls worldwide. Atolls are a major type of coral reefs. They have specific morphological and ecological attributes; but which reef is eventually defined as an atoll varies from author to author [26].

Different areas or habitats within a coral reef do not offer the same level of services and the same level of biological richness. For instance, back reef and lagoon floors dominated by sediments, which can be the product of erosion from the nearby hard-bottom coral reefs, shelter less species than the coral dominated areas and do not yield the same types of services for fisheries, tourism or coastal protection. Protecting $1 \mathrm{~km}^{2}$ of deep sandy lagoon floor does not have the same value for biodiversity and services protection than protecting $1 \mathrm{~km}^{2}$ of shallow coral dominated areas. Protecting $0.5 \mathrm{~km}^{2}$ of both types of habitats seems much more valuable and coherent with balanced representation objectives. We suggest that clear and consistent definition schemes are essential to establish ABT11 progress scores, compare achievements in different regions or countries, and make informed decisions about future policies and priorities at national and international scales.

This paper aims to demonstrate the ranges of scores that can be obtained depending on the definition of, in our case, a coral reef and its habitats. In short, we demonstrate that, for a given region, depending on which features are included in a 'coral reef', results can vary from outstanding scores to poor ones. 
We selected New Caledonia, in the western Pacific Ocean, as a case study, for two reasons. First, New Caledonia's coral reef system is very complex, with numerous habitat configurations. Second, the New Caledonian institutional landscape is also complex. Multiple governance bodies oversee its marine domain.. Both factors - natural and institutional complexity - allow the demonstration that, for the same territory, a large range of habitat protection scores can be achieved. The lessons learned through this case study can be useful for the evaluation of habitat representation within the current protected area networks of most countries worldwide.

\section{Methods}

\subsection{Millennium Coral Reef habitat maps}

Coral reef habitats can be described at scales varying from fine-scale benthic cover inventories, requiring field surveys [24,27], to coarser geomorphological attributes that can be mapped using satellite images, without ground-truthing [28]. To illustrate the influence of habitat definitions on Aichi targets assessment, we used the geomorphological typology and dataset provided by the Millennium Coral Reef Mapping Project (MCRMP). MCRMP defined a globally standardised coral reef geomorphological typology based on satellite imagery (Landsat 7 ETM+ imagery) [29]. The typology uses a five-level classification system. Levels 1 to 4 consist of a hierarchy of geomorphological features with specific attribute names. Level 3, in particular, is an intermediate geomorphological description level that reflects the main structures of a reef complex. Most of the Level 3 classes are related to broad zones and units that are fairly familiar to managers and scientists even if they are not coral reef geomorphology specialists (e.g., barrier reef, fringing reef, patch reef atoll). The most detailed description scheme, Level 5, is a list of 800 different codes and habitats, which 
are defined through unique combinations of Level 1 to 4 features [29]. Any given reef worldwide can have between one and thirty Level 5 classes, for the most complex reefs. In addition, each MCRMP map polygon includes a 'REEF' attribute, which indicates whether the area is sedimentary or has a potentially coral-dominated hard bottom. Because of their exhaustiveness and inter-regional consistency, MCRMP products are cost-efficient tools for regional-scale conservation projects, and MCRMP data have been used for numerous academic and applied studies worldwide, starting with Mora et al. [30].

\subsection{Study site}

New Caledonia is a French overseas territory in the south-western Pacific Ocean. Its characteristics are reviewed in Payri et al. [31]. The archipelago consists of a main continental island, Grande Terre, surrounded by a lagoon that is bordered by a 1,600-kilometer-long barrier reef. Numerous islands, atolls, and reefs of various sizes are located inside the Exclusive Economic Zone, or EEZ [32] (Fig.2). New Caledonia is noted for the remarkable biodiversity of its reefs and for the large variety of geomorphological features occurring in its lagoon and around its islands (Fig.1). The MCRMP dataset identifies over 36,200 $\mathrm{km}^{2}$ of reefs within New Caledonia's 1,450,000-km² EEZ. These reefs are described by 2, 10, 30, 42 and 174 classes at MCRMP Levels 1, 2, 3, 4 and 5 respectively [32].

New Caledonian governance and institutional organizations are complex. Three Provinces share jurisdiction over the inhabited areas. The North and South Provinces manage Grande Terre and several small islands in its close vicinity. The Island Province oversees the Loyalty Islands. The overarching executive power over the three Provinces as well as over remote uninhabited islands (e.g. Chesterfield) is exerted by the Government of New Caledonia. The Government is elected by the Congress, whose members represent the Provinces as well as 
various political groups. The French Government is also present in New Caledonia and controls the services that fall under the sovereign powers of a state, such as immigration, military defence, and economic currency.

The territorial waters (up to 12 nautical miles away from the coasts) of Grande Terre and of the Loyalty Islands are managed by the Provinces, notably in terms of environment and conservation. The remainder of New Caledonia's EEZ is controlled by the Government of New Caledonia. A total of four institutional entities - the three Provinces and the Government - are hence in charge of marine conservation. Each entity has its own spatial domain, legal texts, and management initiatives. In addition, several customary coastal reserves, managed by local communities, occur along New Caledonia's coastline (e.g., the 61-km² customary area of Oundjo, in the North Province).

Excluding the customary reserves, there are seven and twenty-eight protected areas in the North and South Provinces respectively (Table 1). They range from International Union for Conservation of Nature (IUCN) categories I to VI. The Island Province has not yet implemented any MPAs in its territorial waters. Outside the Provinces' territorial waters, the remainder of New Caledonia's EEZ consists of the Natural Park of the Coral Sea (Parc Naturel de la Mer de Corail, or PNMC), established by the Government of New Caledonia in 2014. This is one of the world's largest MPAs (the $4^{\text {th }}$ as of early 2020). A portion of the PNMC corresponds to IUCN category Ia; the rest is under ICUN category II. Figure 2 displays the current extent and IUCN categories of the MPAs in New Caledonia.

Since 2008, six different clusters of the reefs and lagoons of Grande Terre, Isle of Pines, Entrecasteaux atolls, and Ouvea Atoll have been listed as UNESCO World Heritage Area, under the name of Lagoons of New Caledonia; reef diversity and associated ecosystems (Fig. 2, Table 1). This UNESCO area indiscriminately includes zones that are within the spatial domains of the three Provinces as well as of the government. To date, despite numerous 
conservation actions, there are no exhaustive spatial zoning plans for the UNESCO area. There has been no recent MPA creation by the local management committees to effectively regulate it, except for the Entrecasteaux cluster, which is under the authority of the Government, and is a part of the PNMC. It is worth noting that the preliminary report on coral reef protection and $\mathrm{ABT} 11$ achievements in overseas territories issued by [13] included the entire UNESCO area in its inventory of New Caledonian MPAs despite the absence of a zonation and management plan.

The boundaries of the protected areas of each governance zone were compiled into Geographical Information System (GIS) layers from different New Caledonian official sources and from the boundaries specified as latitude-longitude coordinates in legal documents. We did not use the World Database on Protected Areas (WDPA) due to its reportedly poor accuracy in Oceania [22]. As customary reserve boundaries were not available, we did not include them in our inventory of protected areas.

\subsection{Measuring the Aichi 11 representation target}

Using the MCRMP dataset and the UNESCO and MPA limits, we calculated the level of protection of each habitat (i.e., the percentage of the surface area that is protected, or score) for each governance area using the CLIP function of the ESRI ArcGIS $10 \AA$ software. The terrestrial classes ('Land' classes found on atolls, banks, barrier reefs, patch reefs and mainland, Fig. 1) were not considered.

The level of habitat protection was computed at each MCRMP level (Level 1 to 5) and for $\mathrm{REEF}=0-$ sedimentary - and $\mathrm{REEF}=1-$ hard-bottom - areas. Scores were computed for the Provinces and the Government waters separately with respect to their MPAs. In addition, we estimated scores by combining all Government and provincial MPAs, to provide an overall 
result for all New Caledonian waters that are under actual protection. Finally, we calculated scores for the UNESCO zones only, and for all protected areas and UNESCO zones together.

For the Government area, the results displayed in this study are solely based on the extent of the Strict Nature Reserves (IUCN category Ia), where authorized human activities are minimal. At a provincial scale, all MPAs were considered, irrespectively of IUCN categories.

Because five of the six UNESCO clusters do not have spatially explicit zoning plans, we considered the UNESCO areas to either be fully protected or non-protected. This binary view is a simplification of reality, but allows bracketing of the results in terms of best-case and worst-case representation scenarios.

Lastly, we compared the scores that are achieved with the target of obtaining a $10 \%$ representation threshold, and with a 30\% threshold. Indeed, 30\% protection as suggested to be a more realistic threshold to achieve effective biodiversity conservation than $10 \%$ and is often used in systematic conservation planning studies (e.g., $[8,33])$.

\subsection{Rarity bias}

Within a given governance area, certain habitats have a high protection score relative to other habitats. Most of these highly protected habitats occur infrequently and cover small surface areas. If they happen to be within a MPA, it often means that most or all of their surface area is included in that MPA, leading to high protection scores.

To account for this rarity bias, a semi-qualitative metric was used to compare the relative representation of the geomorphologically-defined habitats at each MCRMP Level within the MPA network. Past studies have expressed rarity as the logarithm of the surface area of the habitat of interest divided by the total surface area of the study zone [34]. Building on this 
simple metric, a conservation score with a rarity correction was computed with the following formula:

$$
B=\frac{\frac{a_{i(\text { protected })}}{a_{i(\text { tot })}}}{\left(1-\ln \left(\frac{\left.a_{i(t o t)}\right)}{A}\right)\right)} \times 100 \quad \text { Equation } 1
$$

Where $B$ is the rarity-bias corrected metric, $\mathrm{a}_{\mathrm{i} \text { (protected) }}$ is the protected area of habitat $\mathrm{i}$ within a given governance area, $\mathrm{a}_{\mathrm{i}(\mathrm{tot})}$ is the total area of habitat $\mathrm{i}$ within the same governance area, and A is the total surface area of the same governance area. $B$ varies between 0 and 100,0 being a poor value and 100 representing $100 \%$ protection of a habitat that has a surface area equal to that of the governance zone. Comparing $B$ between habitats allows a more balanced view of the representation of each habitat within MPAs.

\section{Results}

Figure 3 compares the results for all of New Caledonia, based on the MCRMP Levels 2 to 5 attributes. The protected areas considered here are the North and South Province MPAs as well as the government's Strict Nature Reserves (Ia) (thus without the UNESCO areas). These results are compared with the analysis that includes UNESCO zones (considered as protected areas for France Aichi target assessment; Fig. 3). In general, the number of classes reaching the $10 \%$ ABT11 threshold decreases with the increase in habitat description complexity from Levels 2 to 5. Additionally, increasing description complexity leads to higher numbers of classes reaching very high scores.

When the UNESCO zones are included, the 10\% target is met for almost all habitats at every MCRMP Level (except for a few Level 4 and 5 classes). In particular, at Level 5, we note that approximately $59 \%$ of all classes are $100 \%$ protected. These results are in stark contrast to those calculated without accounting for the UNESCO zones. 
The conservation scores achieved by the Government, South Province, North Province and UNESCO zones, at MCRMP Level 3 are very different for each governance zone (Fig.4). Only the Government waters and the UNESCO zones meet ABT11 for most habitat classes. In particular, a fifth of the habitats within the UNESCO zones reach $100 \%$ protection at Level 3. Conversely, three habitats out of fifteen meet the $10 \%$ target for the South Province, and none for the North province. Similar patterns were found for Levels 1, 2, 4, and 5 (not shown).

Habitats reaching very high scores (>90\%) tend to correspond to small-sized scarce habitats. This rarity bias artificially improves overall representation score appraisals. It can be encountered at all levels of description, and is most frequent at Level 5, which is the finest description scheme.

Figure 5 displays the protection scores for each Level 2 habitat contained in the UNESCO zones (ranked from highest to lowest score, from left to right) on the left side, and the corresponding rarity indexes (no units) on the right. Using the same habitat ranking on the $\mathrm{x}$ axes of both plots provides a rapid visual assessment of the impact of the rarity bias on the results.

It is interesting to note that among all MPAs and UNESCO zones, $26,122 \mathrm{~km}^{2}$ of the total surface corresponds to non-reef sedimentary areas $(\mathrm{REEF}=0)$ and $3,663 \mathrm{~km}^{2}$ to hard-bottom reefs $(\mathrm{REEF}=1)$. For the UNESCO zones only, this ratio is $13427 / 2101 \mathrm{~km}^{2}$. For the South Province, it is $400 / 116 \mathrm{~km}^{2}$. The $\mathrm{REEF}=1$ areas reach a score of $78.1 \%$ within all MPAs relative to all of New Caledonia's reefs, $44.8 \%$ within the UNESCO zones relative to all of New Caledonia's reefs, and $12.6 \%$ of protection within the South Province MPAs relative to all the reefs of the South Province. The $10 \%$ threshold is thus met for the broadly defined $\mathrm{REEF}=1$ category. However, the North and the Island Provinces, that possess very limited or 
no MPAs, do not meet the target for the REEF criteria (1.7\% in the North Province; $0 \%$ in the Island Province).

\section{Discussion}

In this study, we considered that ABT11 could be assessed at a detailed level of habitat description. For this, we built upon the CBD texts and guidelines which emphasize the need to protect specific habitats, especially for coral reefs. We pushed the reasoning by measuring the influence upon the conservation scores of the inclusion of specific entities in the definition of a 'coral reef'. To complement this, we identified, at refined description scales, which entities, among those selected to define coral reefs, met the $10 \%$ ABT11 representation level recommended for marine targets in New Caledonia. In doing so, we applied the ecological representation criteria within a clear systematic and hierarchical frame that was initially devised at the scale of habitat entities with sizes ranging from one hundred meters to a few kilometres [29]. We also used the most up-to-date knowledge and data that exhaustively describes the extent and diversity for the reefs and MPAs of New Caledonia.

This study echoes previous work related to adequate mapping of coral reefs, and to the subsequent reliability of habitat representation calculations, in the view of quantifying an area's progress towards international conservation objectives. For instance, Wabnitz et al. [35] drew upon the MCRMP to discuss the need to have consistent and accurate maps to assess international commitments. In this study however, we did not take into account mapping issues and we considered the estimates of habitat areas to be reliable. This study is also not the first to use MCRMP data to investigate coral reef conservation gaps or achievements. MCRMP was used by Mora et al. [30] to measure the MPA coverage of coral reefs globally. Andréfouët and Hamel [36] used it in a methodological paper to demonstrate 
how conservation gaps can be identified with metadata. Lastly, various authors have conducted national or regional conservation gap analyses with systematic conservation planning software and MCRMP data (e.g., the Government of Papua New Guinea [37]). However, to our knowledge, this is the first time that MCRMP data are used in the context of Aichi Target assessments. Beyond coral reefs, gap analyses and evaluation of conservation targets are regularly conducted for various ecoregions worldwide [38]. This study indirectly confirms the value of remote sensing-derived data (such as MCRMP habitat maps) for such assessments [39], and specifically for coral reefs. The results for New Caledonia clearly highlight that all habitats within a coral reef are not equally protected.

The New Caledonia case study highlights that Aichi Target 11 achievements can be variable within the same country depending on how fragmented its governance areas are. Multiple governance areas are most likely to create contrasted patterns of achievement. The consequences are that even if representation is a key driver of the analysis, some habitats might not be represented at all if they are specific to a governance area that lacks adequate MPA coverage. This for instance is the case of Ouvea atoll in the Loyalty Island. Ouvea is the only partly uplifted atoll of New Caledonia [32]. It is part of the UNESCO areas, but it does not possess any legal protection.

In New Caledonia, low habitat protection is most striking in governance areas with limited MPA coverage, such as the in North Province's territorial waters. In contrast, the Government area mostly meets the ABT11 at all levels of description. The goals are met for $100 \%, 66 \%$, $66 \%, 73 \%$ and $78 \%$ of the habitats for the MCRMP Level 1 (which includes 1 habitat), Level 2 (3 habitats), Level 3, (9 habitats), Level 4 (23 habitats) and Level 5 (28 habitats) respectively. For the government, habitats at any MCRMP level that did not meet the $10 \%$ threshold actually had null scores ( $0 \%$ protection). These correspond to the Level 3 'drowned bank', 'drowned atoll', or 'oceanic island' habitats (and related Level 4 and 5 habitats), which 
are absent from the Strict Nature Reserve areas. This gap could be filled by protecting new zones that include these habitats. However, these results are based on the extent of the Strict Nature Reserves (IUCN category Ia) only. If IUCN category II areas are included in our census, this representation issue is solved because all the Government area is protected as part of the PNMC (leading to $100 \%$ representation of all habitats).

Our results demonstrate that the conservation strategy employed by the New Caledonian Government to implement the PNMC is an efficient method of meeting ABT11-type strategies in remote areas. The PNMC consists of a very large MPA. Its current zoning plan was defined and put in place by the Government within 4 years of its creation. The rapidity of the implementation is notably due to the limited amount of anthropogenic activities occurring in the remote parts of New Caledonia's EEZ. In contrast, the Provinces, which are in charge of populated areas, where there are numerous stakeholders and conflicting activities, face many issues in terms of conservation planning. Progress is slower, and the possibility of establishing large MPAs to rapidly increase ABT11 scores is limited. Despite this, based on the $\mathrm{REEF}=1$ attribute (broad coral reef definition), the South Province's MPAs meet the 10\% threshold - as over $12 \%$ of reefs are protected. The limited MPAs in the South Province are hence relatively efficient in terms of reef habitat protection. However, the North and Island Provinces are far from reaching the $10 \%$ threshold for the REEF habitat. The uninhabited areas of the Grand Lagon Nord and the Beautemps Beaupré atoll would be good candidates to improve ABT11 achievements, at least in terms of the REEF criteria. Systematic conservation planning software, such as Marxan, could help to identify more precisely areas that could be included in future MPAs, potentially by prioritising areas that already possess strong customary no-go or no-take policies. This would maximise compliance by local populations and make these uncharted areas more attractive for tourism. 
If the UNESCO zones are considered to be protected areas, New Caledonia's EEZ meets the 10\% protection threshold for most MCRMP habitats, and at any level of description (Fig. 3). This is the official statement currently put forward by the AFB (2019). However, it is an optimistic estimate. Although fishing regulations are in place within the UNESCO zones, due to provincial-level regulations, and although numerous conservation programs explicitly embedded within the UNESCO framework are currently being designed, the lack of legallybinding spatially-explicit management plan in five of the six UNESCO clusters impedes any unambiguous conclusion about habitat protection scores. For now, the habitat protection granted by the best- and worst-case scenarios (with or without the UNESCO zones) is presented in Fig.3. Following on this line of thought, we emphasize that any ABT11 assessment globally should take into consideration the effectiveness and enforcement of MPA regulations on a case-by-case basis.

This paper has shown that, for New Caledonia, the range of habitat protection scores that can be obtained strongly depends on how coral reefs and their habitats are defined and described. In light of our results, the statement that at least $10 \%$ of all coral reef habitats are protected in New Caledonia needs to be modulated. Obvious gaps exist for some major reef habitats, even within the governance area which possesses the largest MPAs (e.g., Level 3 'Drowned banks' have no protection in the Government's Ia reserves), and habitat rarity is a factor to take into consideration for sound quantifications. One index of rarity has been used here to highlight the need to carefully investigate the results, as very high scores can be caused by habitats with limited coverage. The index used here is one of many other rarity metrics suitable for such evaluations.

This study was specific to coral reefs, and we used New Caledonia as a case study. In other coral reef regions (data not shown, but for Indonesia for instance), the trends are similar. Differences in ABT11 achievements arise from variations in levels of habitat description, and 
rarity biases occur. A particularity of coral reefs is their inherent mosaics of contrasted habitats with different properties, thus justifying an assessment per habitat as we conducted here. However, generalizing the findings from this New Caledonia coral reef case study to other coastal or terrestrial ecosystems cannot be immediate. Although all ecoregions can be described through hierarchical descriptions, not all have been mapped and not all of the components of some ecoregions require such multilevel descriptions. Nevertheless, we encourage other countries, governance areas and CBD to assess the representation scores critically, using consistent and clear definitions and, if possible, datasets. A generalization of similar approaches to coastal environments should i) bring common references, ii) frame objectively scores per region and between regions, iii) identify conservation gaps, iv) help inferring targeted quantitative conservation recommendations and relevant policies for after 2020.

\section{Acknowledgements}

Marine Protected Area GIS layers were partly provided by the Affaires Maritimes de Nouvelle-Calédonie, the Conservatoire des Espaces Naturels and through the http://www.georep.nc/ information system of New Caledonia. The Millennium Coral Reef Mapping Project was initially funded by NASA grants NAG5-10908 to SA and Frank MullerKarger (University of South Florida), and grant CARBON-0000-0257 to Julie Robinson (NASA). The project is now funded by Institut de Recherche pour le Développement. We thank the reviewer for criticisms and inputs that clarified and enhanced the paper. This is ENTROPIE contribution \#422.

\section{Supplementary material}


The correspondence between codes and explicit labels for the Level 3 of the Millennium Coral Reef Mapping Project occurring in New Caledonia is available online (File SM1.doc).

\section{References}

[1] H.L. Thomas, B. Macsharry, L. Morgan, N. Kingston, R. Moffitt, D. Stanwell-Smith, L. Wood, Evaluating official marine protected area coverage for Aichi Target 11: appraising the data and methods that define our progress: Aquatic Conserv: Mar. Freshw. Ecosyst. 24 (2014) 8-23. https://doi.org/10.1002/aqc.2511.

[2] C.J. Klein, C.J. Brown, B.S. Halpern, D.B. Segan, J. McGowan, M. Beger, J.E.M. Watson, Shortfalls in the global protected area network at representing marine biodiversity, Sci Rep. 5 (2015) 17539. https://doi.org/10.1038/srep17539.

[3] L. Boonzaier, D. Pauly, Marine protection targets: an updated assessment of global progress, Oryx. 50 (2016) 27-35. https://doi.org/10.1017/S0030605315000848.

[4] R.L. Singleton, C.M. Roberts, The contribution of very large marine protected areas to marine conservation: Giant leaps or smoke and mirrors?, Marine Pollution Bulletin. 87 (2014) 7-10. https://doi.org/10.1016/j.marpolbul.2014.07.067.

[5] R. Devillers, R.L. Pressey, A. Grech, J.N. Kittinger, G.J. Edgar, T. Ward, R. Watson, Reinventing residual reserves in the sea: are we favouring ease of establishment over need for protection?: Aquatic Conserv: Mar. Freshw. Ecosyst. 25 (2015) 480-504. https://doi.org/10.1002/aqc.2445.

[6] S.E. Rees, N.L. Foster, O. Langmead, S. Pittman, D.E. Johnson, Defining the qualitative elements of Aichi Biodiversity Target 11 with regard to the marine and coastal environment in order to strengthen global efforts for marine biodiversity conservation outlined in the United Nations Sustainable Development Goal 14, Marine Policy. 93 (2018) 241-250. https://doi.org/10.1016/j.marpol.2017.05.016.

[7] C.R. Margules, R.L. Pressey, Systematic conservation planning, Nature. 405 (2000) 11.

[8] M. Deas, S. Andréfouët, M. Léopold, N. Guillemot, Modulation of Habitat-Based Conservation Plans by Fishery Opportunity Costs: A New Caledonia Case Study Using Fine-Scale Catch Data, PLoS ONE. 9 (2014) e97409. https://doi.org/10.1371/journal.pone.0097409.

[9] S. Van Wynsberge, S. Andréfouët, N. Gaertner-Mazouni, J. Tiavouane, D. Grulois, J. Lefèvre, M.L. Pinsky, C. Fauvelot, Considering reefscape configuration and composition in biophysical models advance seascape genetics, PLoS ONE. 12 (2017) e0178239.

[10] S. Woodley, B. Bertzky, N. Crawhall, N. Dudley, J.M. Londoño, K. MacKinnon, K. Redford, Meeting AICHI TARGET 11: What does success look like for protected area systems?, 18 (2012) 14.

[11] M.D. Spalding, H.E. Fox, G.R. Allen, N. Davidson, Z.A. Ferdaña, M. Finlayson, B.S. Halpern, M.A. Jorge, A. Lombana, S.A. Lourie, K.D. Martin, E. McManus, J. Molnar, C.A. Recchia, J. 
Robertson, Marine Ecoregions of the World: A Bioregionalization of Coastal and Shelf Areas, BioScience. 57 (2007) 573-583. https://doi.org/10.1641/B570707.

[12] Convention on Biological Diversity, Quick guide to the Aichi Biodiversity Targets. (downloaded 06/03/2020 at https://www.cbd.int/doc/strategic-plan/targets/T11-quick-guide-en.pdf)

[13] AFB. 2019. Outre-mer français. La protection spatiale des récifs coralliens. 98 p. Available from http://www.forum-aires-marines.fr/Actualites/Outre-Mer-etat-des-lieux-de-la-protectionspatiale-des-recifs-coralliens (accessed August 2019).

[14] C. Payri, B. Richer de Forges, Compendium of marine species from New Caledonia Documents Scientifiques et Techniques IRD, Noumea, II.7 (2006), 441 p.

[15] C. Quétel, S. Marinesque, D. Ringler, L. Fillinger, T. Changeux, C. Marteau, M. Troussellier, Iles Eparses (SW Indian Ocean) as reference ecosystems for environmental research, Acta Oecologica. 72 (2016) 1-8. https://doi.org/10.1016/j.actao.2015.12.012.

[16] S. Andréfouët, M. Adjeroud, French Polynesia, World Seas: an Environmental Evaluation, Sheppard C, editor. Elsevier. 2 The Indian Ocean to the Pacific (2018) 827-853. ISBN:9780081008539

[17] J. Amengual, D. Alvarez-Berastegui, A critical evaluation of the Aichi Biodiversity Target 11 and the Mediterranean MPA network, two years ahead of its deadline, Biological Conservation. 225 (2018) 187-196. https://doi.org/10.1016/j.biocon.2018.06.032

[18] A. Fischer, D. Bhakta, M. Macmillan-Lawler, P. Harris, Existing global marine protected area network is not representative or comprehensive measured against seafloor geomorphic features and benthic habitats, Ocean \& Coastal Management. 167 (2019) 176-187. https://doi.org/10.1016/j.ocecoaman.2018.10.001.

[19] N. Zafra-Calvo, E. Garmendia, U. Pascual, I. Palomo, N. Gross-Camp, D. Brockington, J.-A. Cortes-Vazquez, B. Coolsaet, N.D. Burgess, Progress toward Equitably Managed Protected Areas in Aichi Target 11: A Global Survey, BioScience. 69 (2019) 191-197. https://doi.org/10.1093/biosci/biy143.

[20] K. Jantke, C.D. Kuempel, J. McGowan, A.L.M. Chauvenet, H.P. Possingham, Metrics for evaluating representation target achievement in protected area networks, Divers Distrib. 25 (2019) 170-175. https://doi.org/10.1111/ddi.12853.

[21] C. House, D. Redmond, M.R. Phillips, An assessment of the efficiency and ecological representativity of existing marine reserve networks in Wales, UK, Ocean \& Coastal Management. 149 (2017) 217-230. https://doi.org/10.1016/j.ocecoaman.2017.04.016.

[22] P. Smallhorn-West, H. Govan, Towards reducing misrepresentation of national achievements in marine protected area targets, Marine Policy. 97 (2018) 127-129. https://doi.org/10.1016/j.marpol.2018.05.031.

[23] E. Lewis, B. MacSharry, D. Juffe-Bignoli, N. Harris, G. Burrows, N. Kingston, N.D. Burgess, Dynamics in the global protected-area estate since 2004, Conservation Biology. 33 (2019) 570579. https://doi.org/10.1111/cobi.13056.

[24] Andréfouët S. 2011. Reef typology. Pages 906-910 in Hopley D, editor. Encyclopedia of modern coral reefs. Springer, Dordrecht.

[25] Done T. 2011. Coral reef, Definition. Pages 261-267 in Hopley D, editor. Encyclopedia of modern coral reefs. Springer, Dordrecht. 
[26] W.M Goldberg. Atolls of the world: revisiting the original chek-list. Atoll Research Bulletin. 610 (2016) 1-47.

[27] P.J. Mumby, A.R. Harborne, Development of a systematic classification scheme of marine habitats to facilitate regional management and mapping of Caribbean coral reefs, Biological Conservation. 88 (1999) 155-163.

[28] S. Andréfouët, Coral reef habitat mapping using remote sensing: A user vs producer perspective. implications for research, management and capacity building, Journal of Spatial Science. 53 (2008) 113-129. https://doi.org/10.1080/14498596.2008.9635140.

[29] S.A Andréfouët, F.E Muller-Karger, J.A. Robinson, C.J. Kranenburg, D. Torres-Pulliza, S.A. Spraggins, B. Murch, Global assessment of modern coral reef extent and diversity for regional science and management applications: a view from space,. Proceedings of 10th International Coral Reef Symposium. Okinawa. (2006) 1: 1732-1745.

[30] C. Mora, S. Andréfouët, M.J. Costello, C.J. Kranenburg, A. Rollo, J.E.N. Veron, K. Gaston, R. Myers, Coral Reefs and the Global Network of Marine Protected Areas, Science. 312 (2006) 1750-1751. https://doi.org/10.1126/science.1125295.

[31] C. Payri , V. Allain, J. Aucan, C. David, V. David, C. Dutheil, L. Loubersac, C. Menkes, B. Pelletier, G. Pestana, S. Samadi, New Caledonia, World Seas: an Environmental Evaluation, Sheppard C, editor, Elsevier, 2 The Indian Ocean to the Pacific (2018) 593-618. ISBN:9780081008539

[32] S. Andréfouët, G. Cabioch, B. Flamand, B. Pelletier, A reappraisal of the diversity of geomorphological and genetic processes of New Caledonian coral reefs: a synthesis from optical remote sensing, coring and acoustic multibeam observations, Coral Reefs. 28 (2009) 691-707. https://doi.org/10.1007/s00338-009-0503-y.

[33] M.A. Hamel, S. Andréfouët, R.L. Pressey, Compromises between international habitat conservation guidelines and small-scale fisheries in Pacific island countries: Conservation and fisheries in Pacific islands, Conservation Letters. 6 (2013) 46-57. https://doi.org/10.1111/j.1755-263X.2012.00285.x.

[34] I. Duarte, F.C. Rego, J.P. Casquilho, P. Arsénio, A Relevance Index for the habitat areas of Natura 2000 Network based on their Rarity and Representativeness, Ecological Indicators. 61 (2016) 202-213. https://doi.org/10.1016/j.ecolind.2015.09.015.

[35] C.C. Wabnitz, S. Andréfouët, F.E. Muller-Karger, Measuring progress toward global marine conservation targets, Frontiers in Ecology and the Environment. 8 (2010) 124-129. https://doi.org/10.1890/080109.

[36] S. Andréfouët, M.A. Hamel, Tropical islands quick data gap analysis guided by coral reef geomorphological maps, Marine Pollution Bulletin. 81 (2014) 191-199. https://doi.org/10.1016/j.marpolbul.2014.01.055.

[37] Government of Papua New Guinea. 2015. National Marine Conservation Assessment for Papua New Guinea. Conservation and Environment Protection Authority. Port Moresby.

[38] S.H.M. Butchart, M. Clarke, R.J. Smith, R.E. Sykes, J.P.W. Scharlemann, M. Harfoot, G.M. Buchanan, A. Angulo, A. Balmford, B. Bertzky, T.M. Brooks, K.E. Carpenter, M.T. ComerosRaynal, J. Cornell, G.F. Ficetola, L.D.C. Fishpool, R.A. Fuller, J. Geldmann, H. Harwell, C. Hilton-Taylor, M. Hoffmann, A. Joolia, L. Joppa, N. Kingston, I. May, A. Milam, B. Polidoro, G. Ralph, N. Richman, C. Rondinini, D.B. Segan, B. Skolnik, M.D. Spalding, S.N. Stuart, A. Symes, J. Taylor, P. Visconti, J.E.M. Watson, L. Wood, N.D. Burgess, Shortfalls and Solutions 
for Meeting National and Global Conservation Area Targets: Meeting conservation area targets, Conservation Letters. 8 (2015) 329-337. https://doi.org/10.1111/conl.12158.

[39] B. O'Connor, C. Secades, J. Penner, R. Sonnenschein, A. Skidmore, N.D. Burgess, J.M. Hutton, Earth observation as a tool for tracking progress towards the Aichi Biodiversity Targets, Remote Sens Ecol Conserv. 1 (2015) 19-28. https://doi.org/10.1002/rse2.4.

[40] Andréfouët S, Chagnaud N, Chauvin C, Kranenburg C. 2008. Atlas of the French overseas coral reefs. Centre IRD de Nouméa, Nouméa, Nouvelle-Calédonie. CD-ROM. 


\section{Figure legends}

Figure 1: Top. Map of New Caledonia displaying its islands, atolls, and reefs, when described at Level 3 of the Millennium Coral Reef Mapping Project. Although not all classes are visible at that scale, the caption and number of all classes are shown below the map. Bottom: details for two atolls and one bank of the Entrecasteaux group, at Level 3 (left) and Level 5 (right) of descriptions. The caption details of the Level 5 classes are not shown. Details and maps at Level 5 for all of New Caledonia are provided in [40].

Figure 2: Map of the protected areas by governance in New Caledonia. The boundaries of the UNESCO World Heritage Areas are also shown.

Figure 3: Scores of protection (in percent) sorted from the highest to lowest value attained by each habitat at the Levels 2 to 5 of the Millennium Coral Reef Mapping Project. The dark grey colour shows values achieved with North and South Province MPAs, and the government's Strict Nature Reserves (Ia). The light grey colour represents the scores achieved for the North and South Province MPAs, the government's Strict Nature Reserves and the UNESCO areas.

Figure 4: Scores of protection (percentage) sorted by decreasing value achieved by MPAs in various governance zones at the Millennium Coral Reef Mapping Project (MCRMP) Level 3. The $\mathrm{x}$-axis provides the MCRMP Level 3 code of each habitat; the corresponding attributes are described in Supporting Information.

Figure 5: Comparison of the scores for Level 2 habitats in the UNESCO zones before and after taking into account their rarity. Habitats 2 (Oceanic Uplifted/filled Atoll) and 8 (Continental Island) achieved a high score (left panel), that is moderated by taking into account the high rarity of these habitats: their relative contribution to conservation is low (right panel). The best-protected habitat on the right is habitat 13 (Shelf Marginal Structures) which is both highly protected (67\%) and has a large area (40\% of the total extent of all coral reef habitats in New Caledonia's EEZ). 

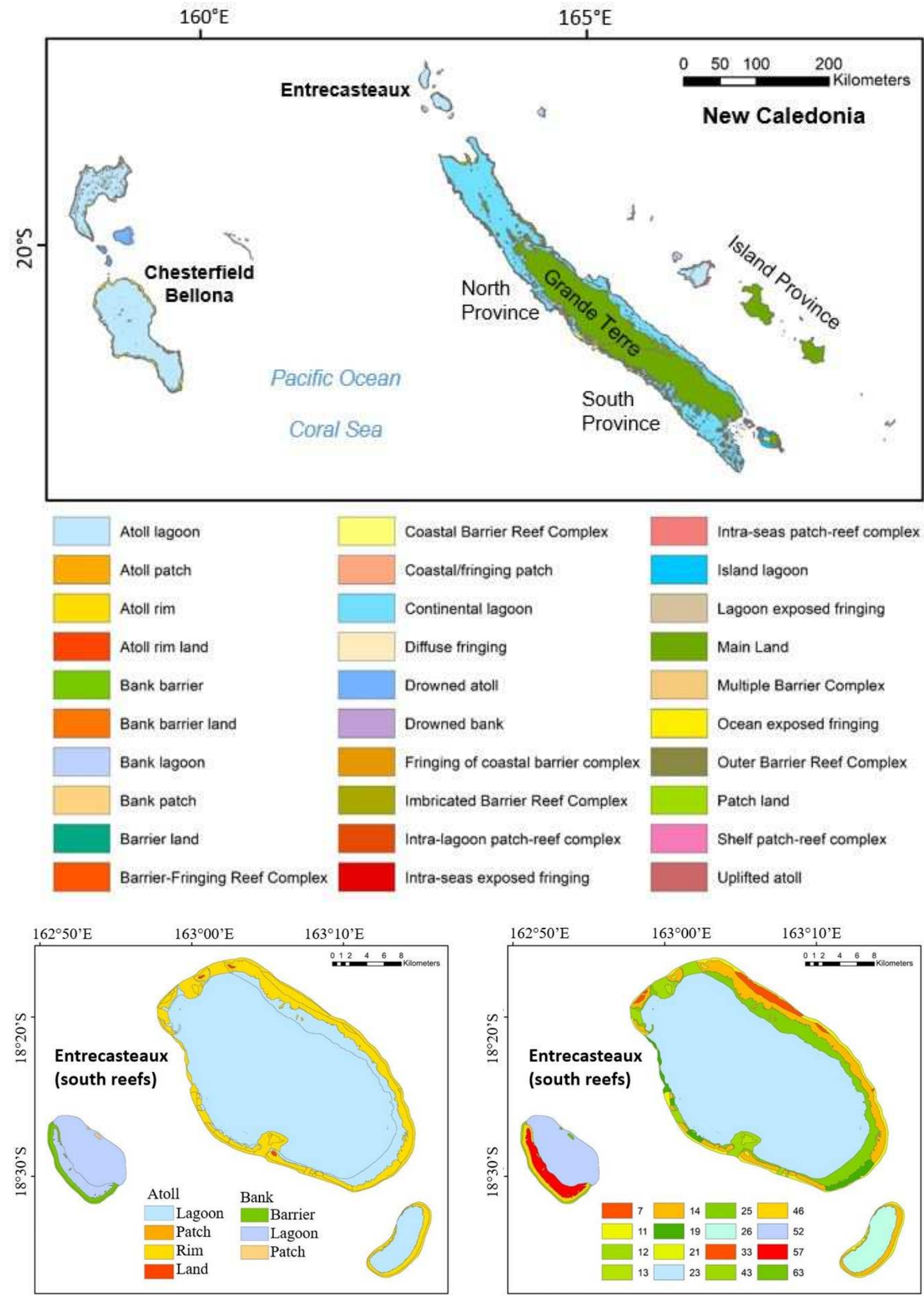

Figure 1: Top. Map of New Caledonia displaying its islands, atolls, and reefs, when described at Level 3 of the Millennium Coral Reef Mapping Project. Although not all classes are visible at that scale, the caption and number of all classes are shown below the map. Bottom: details 
for two atolls and one bank of the Entrecasteaux group, at Level 3 (left) and Level 5 (right) of descriptions. The caption details of the Level 5 classes are not shown. Details and maps at Level 5 for all of New Caledonia are provided in [40]. 


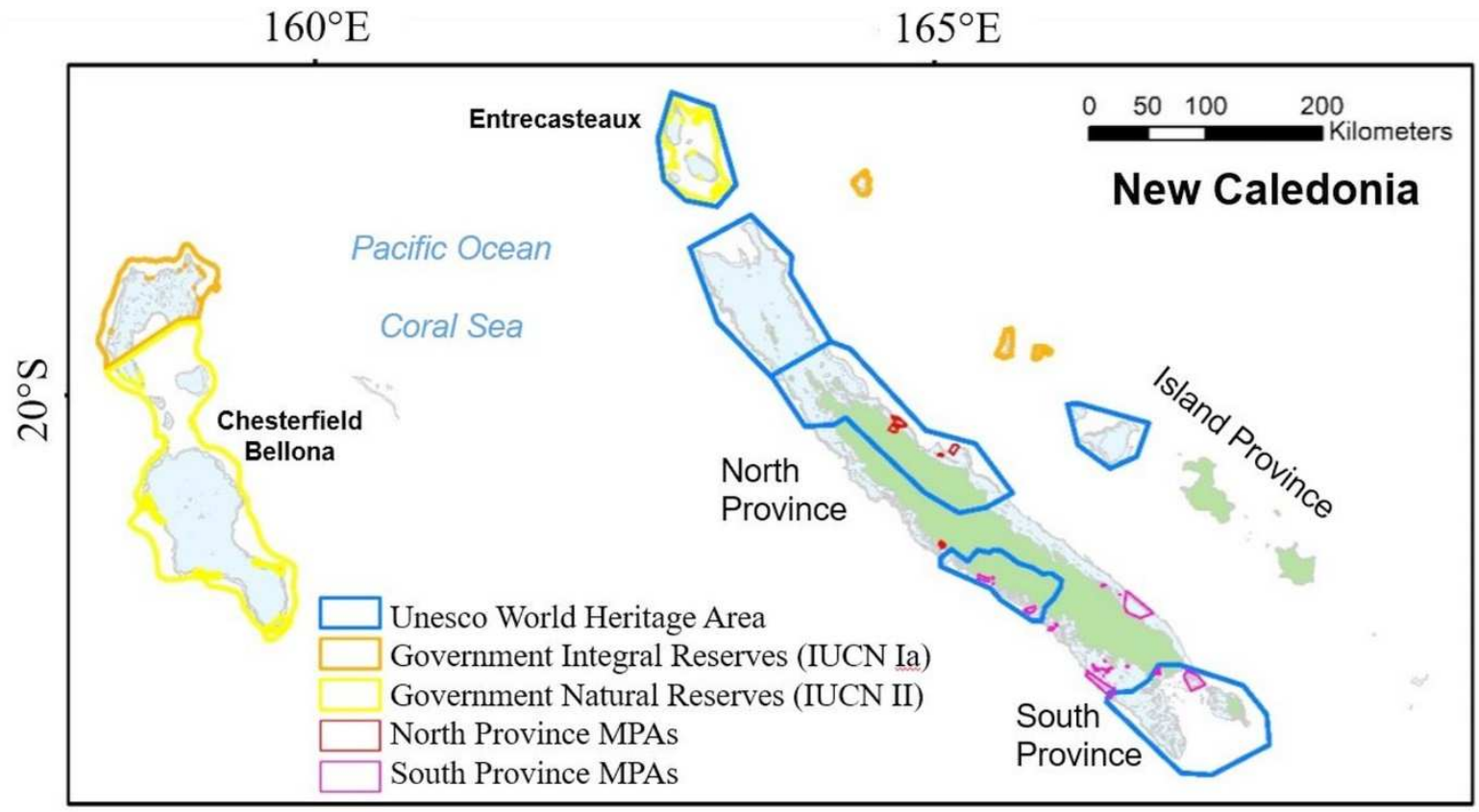

Figure 2: Map of the protected areas by governance in New Caledonia. The boundaries of the UNESCO World Heritage Areas are also shown. 

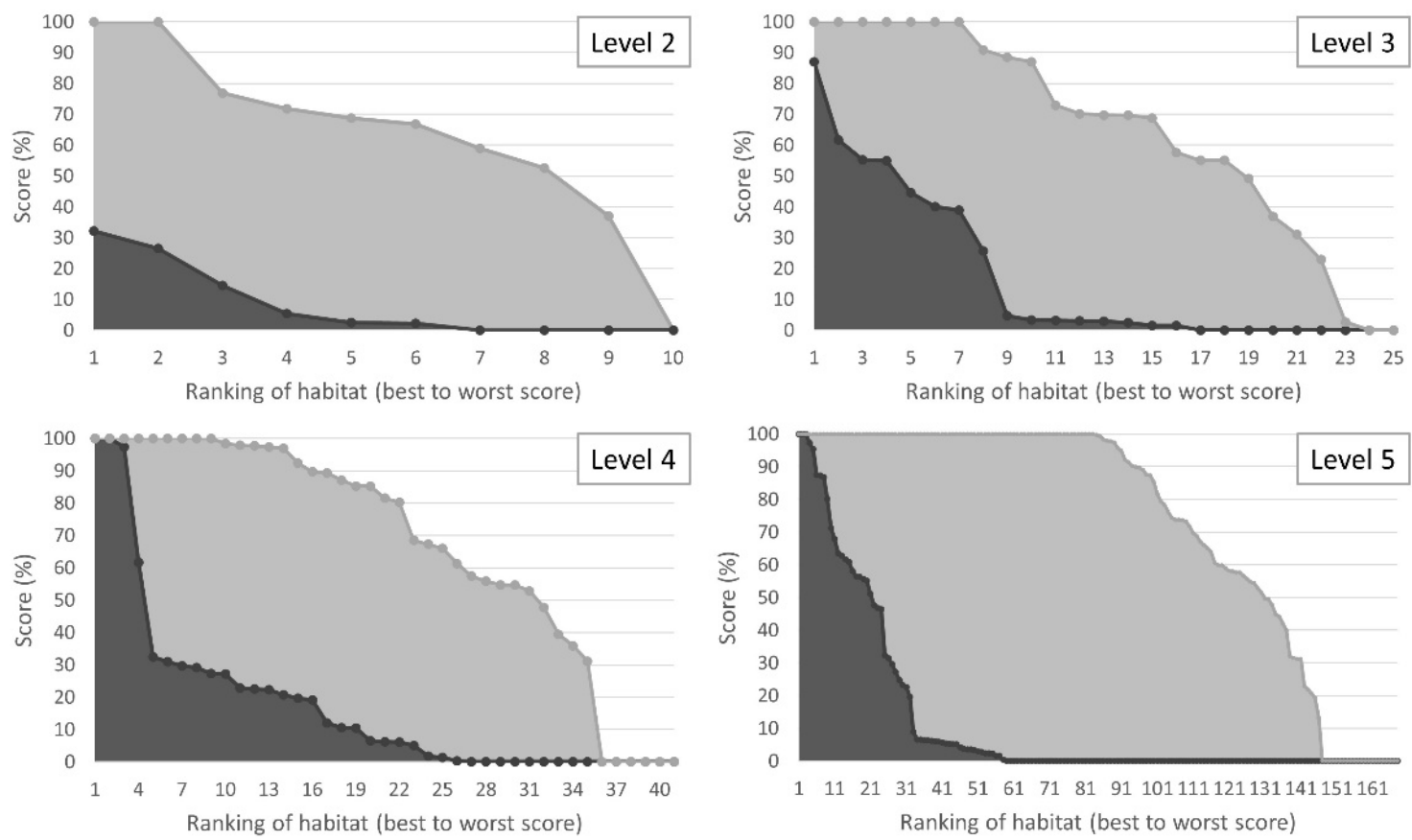

- UNESCO zone, Governmental (IUCN Ia) and Provincial (all IUCN categories) MPAs

- Governmental (IUCN la) and Provincial (all IUCN categories) MPAs

Figure 3: Scores of protection (in percent) sorted from the highest to lowest value attained by each habitat at the Levels 2 to 5 of the Millennium Coral Reef Mapping Project. The dark grey colour shows values achieved with North and South Province MPAs, and the government's Strict Nature Reserves (Ia). The light grey colour represents the scores achieved for the North and South Province MPAs, the government's Strict Nature Reserves and the UNESCO areas. 

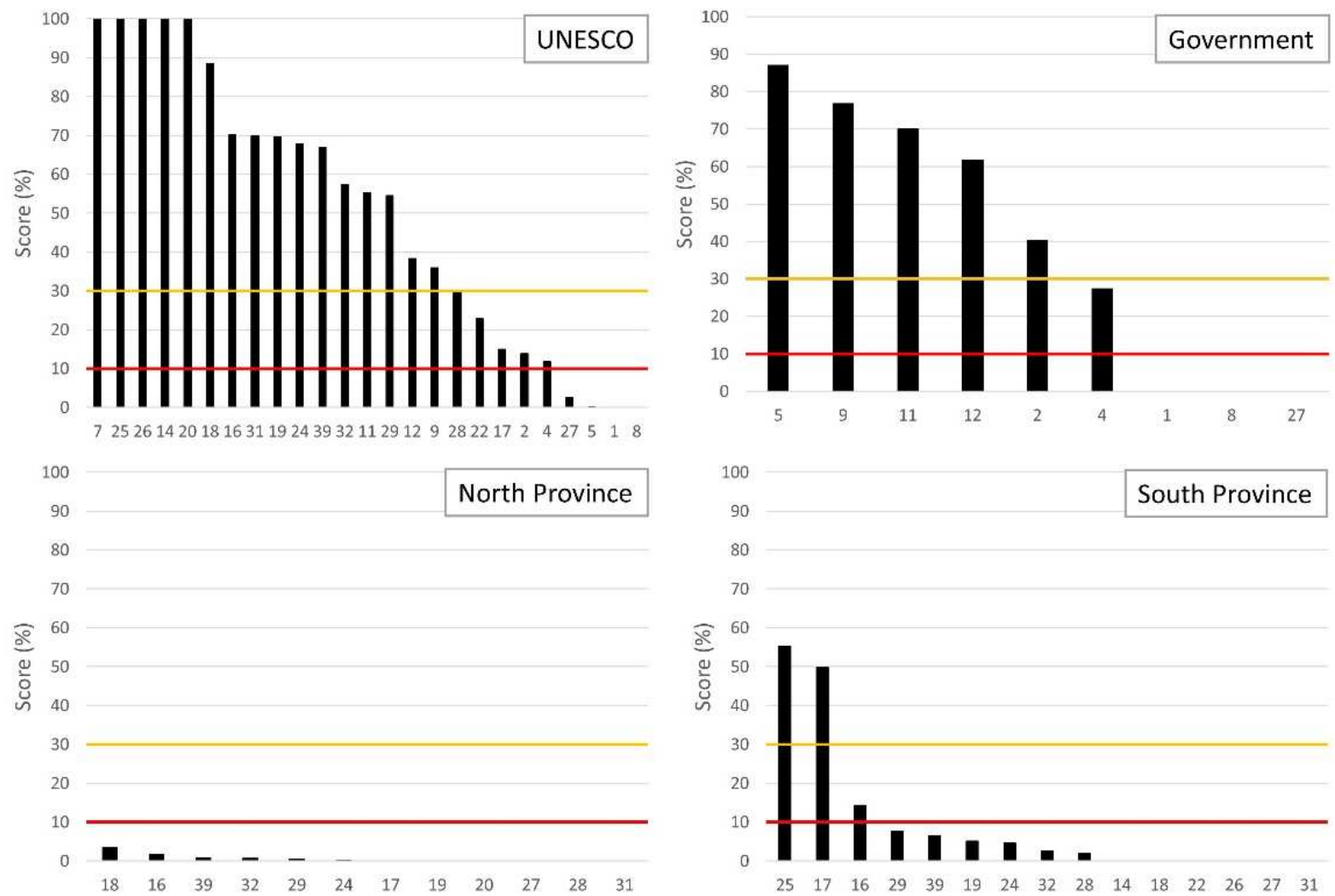

Figure 4: Scores of protection (percentage) sorted by decreasing value achieved by MPAs in various governance zones at the Millennium Coral Reef Mapping Project (MCRMP) Level 3. The $\mathrm{x}$-axis provides the MCRMP Level 3 code of each habitat; the corresponding attributes are described in Table SM1; as Supporting Information. 

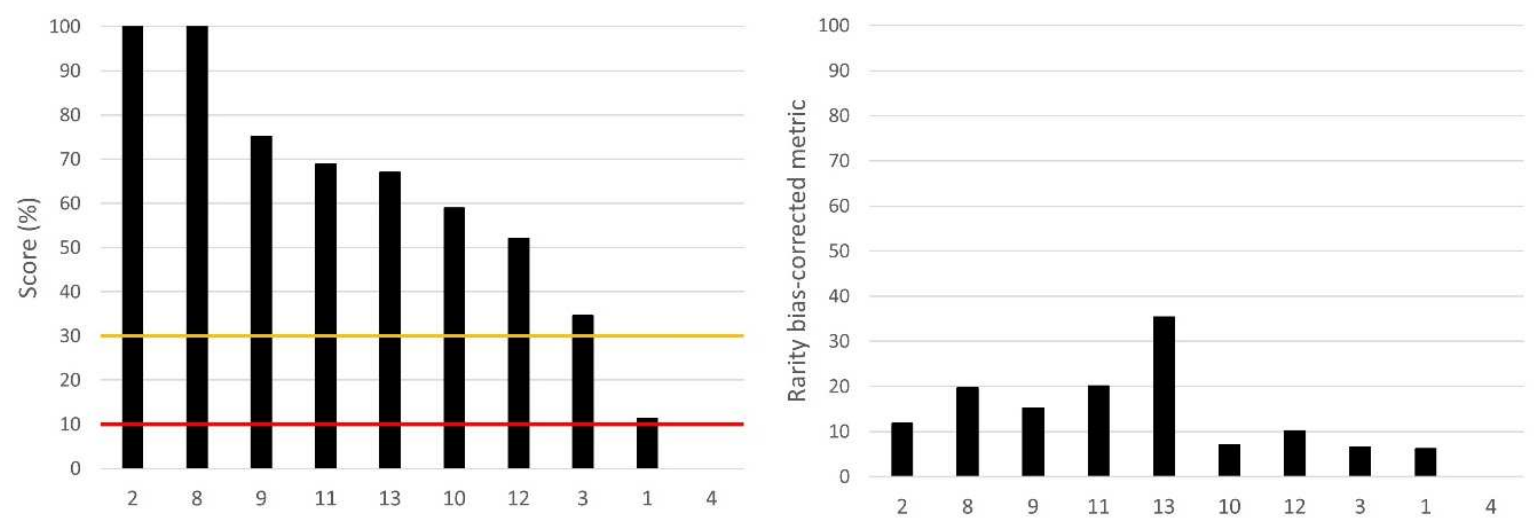

Figure 5: Comparison of the scores for Level 2 habitats in the UNESCO zones before and after taking into account their rarity. Habitats 2 (Oceanic Uplifted/filled Atoll) and 8 (Continental Island) achieved a high score (left panel), that is moderated by taking into account the high rarity of these habitats: their relative contribution to conservation is low (right panel). The best-protected habitat on the right is habitat 13 (Shelf Marginal Structures) which is both highly protected $(67 \%)$ and has a large area (40\% of the total extent of all coral reef habitats in New Caledonia's EEZ). 
Table 1: Governance area of each institution managing coral reef in New Caledonia.

Institution Governance area

Government New Caledonia's EEZ excluding the areas managed by the Provinces

Only the strict nature reserves (IUCN Ia) were considered in our analysis

Total and protected areas: 15,029 and 4,270 $\mathrm{km}^{2}$.

North Province $\quad$ North part of Grande Terre and nearby islands (Belep, Yandé, Balabio, etc.):

internal and territorial waters (12 nautical miles)

Total and protected areas: 13,439 and $125 \mathrm{~km}^{2}$.

South Province South part of Grande Terre and nearby islands (Ile of Pines, Ouen, etc.): internal and territorial waters (12 nautical miles)

Total and protected areas: 6,460 and $517 \mathrm{~km}^{2}$.

Island Province Internal and territorial waters (12 nautical miles). The largest islands are Lifou,

Ouvéa and Maré.

Total and protected areas: $1,293 \mathrm{~km}^{2}$. No MPAs.

UNESCO UNESCO Lagoons of New Caledonia six zones or clusters: Grand Lagon Sud, Zone Côtiere Ouest, Grand Lagon Nord, Zone Côtiere Nord-Est, Entrecasteaux Atolls and the Ouvéa-Beautemps Beaupré Atolls.

UNESCO area: $15,530 \mathrm{~km}^{2}$. 


\section{Supplementary Information}

Table SM1: Correspondence between Level 3 codes and their descriptions.

\begin{tabular}{|c|l|}
\hline Level 3 Code & \multicolumn{1}{|c|}{ Level 3 Description } \\
\hline 1 & Drowned atoll \\
\hline 2 & Atoll rim \\
\hline 4 & Atoll lagoon \\
\hline 5 & Atoll patch \\
\hline 7 & Uplifted atoll \\
\hline 8 & Drowned bank \\
\hline 9 & Bank barrier \\
\hline 11 & Bank lagoon \\
\hline 12 & Bank patch \\
\hline 14 & Island lagoon \\
\hline 16 & Outer Barrier Reef Complex \\
\hline 17 & Multiple Barrier Complex \\
\hline 18 & Imbricated Barrier Reef Complex \\
\hline 19 & Coastal Barrier Reef Complex \\
\hline 20 & Barrier-Fringing Reef Complex \\
\hline 22 & Coastal/fringing patch \\
\hline 24 & Intra-lagoon patch-reef complex \\
\hline 25 & Intra-seas patch-reef complex \\
\hline 26 & Shelf patch-reef complex \\
\hline 27 & Ocean exposed fringing \\
\hline 28 & Intra-seas exposed fringing \\
\hline 29 & Lagoon exposed fringing \\
\hline 31 & Diffuse fringing \\
\hline 32 & Fringing of coastal barrier complex \\
\hline 39 & Continental lagoon \\
\hline & \\
\hline
\end{tabular}

